ISSN: 2639-359X

Volume 2, Issue 1, 2019, PP: 14-17

\title{
Elderly Dental Patients with Renal Diseases
}

\section{Ćatović Adnan ${ }^{1 *}$, Ćatović Džana ${ }^{2}$, Ćatović Dina ${ }^{3}$}

${ }^{1}$ Croatian Academy of Medical Sciences, Retired Professor of Geriatric Dentistry School of Dental Medicine, Zagreb, Croatia.

${ }^{2,3}$ dr. med. dent. Folktandvården, Säter Municipality, Sweden.

*Corresponding Author: Professor Adnan Ćatović, DMD.MSc., PhD, Croatian Academy of Medical Sciences, Zagreb, Croatia.E-mail: catovic282@gmail.com

\begin{abstract}
Increasing life expectancy affects the enlargement of elderly dental patients. Elderly are affect usually by one or few chronic diseases and have physiological changes following their age. Changes in the oral cavity have 90\% of patients with chronic renal disease on soft tissues and alveolar bone. Gingival hyperplasia as one of the side effects of drug administration is one of the most commonly described oral manifestations in patients with kidney failure. Patients in the final phase of kidney failure tend to have bleeding, so it is advisable to perform dental procedures in the days between dialysis. It is advisable to do the blood test and a small coagulogram before oral surgery procedures and good local hemostasis-compression and suture, if needed, after the procedure. As a part of renal osteodystrophy, demineralization, trabecularity and loss of the maxillary and mandibular cortical bone, bone damage (bone fractures) during dental surgery (tooth extraction) may occurs. The proper maintaining of oral hygiene in elderly patients is emphasize to avoid general health and chronical renal illness complications.
\end{abstract}

Keywords: elderly, oral health, coagulogram, renal diseases, gingival hyperplasia

\section{INTRODUCTION}

Great progress in diagnosing, treating and preventing many life-threatening illnesses leads to an ever-growing share of the elderly population in the developed world. According to the complexity of elderly health care, an interdisciplinary approach to the health of these people is need. The interdisciplinary team needs to apply the appropriate model of prevention and therapy in the oral health domain. In 2016, the World Dental Association (FDI) adopted a new definition of oral health that : Oral health is multi significant and includes the ability to speak, laugh, smell, taste, touch, chew, swallow and can reliably manifest facial expressions through the range of emotions. It includes also the absence of pain, discomfort and illness in the face and head area of each person. Oral health is a fundamental component of overall health, physical and mental prosperity. It is constantly under the influence of the values and attitudes between person and the surrounding. This definition of oral health confirms the well-known fact that oral and general health are interrelated, emphasizing holistic approach to the patient. The best confirmation for this thesis is multidisciplinary approach of all branches of medicine and dental medicine in nowadays therapy of elderly dental patients $(1,2)$

Individuals of older age are the special group of patients and in many ways different from children and adolescents. Why are older people more special than other age groups? They have health problems affecting the care of mouth and teeth. Medications that they take may interact with medication and the procedures used in general dental practice. Elderly very often suffers from the lack of motivation, inability to adapt on everyday life and communication difficulties. They are affect usually by one or few chronic diseases / diabetes, cancer, vascular, renal and heart disease. /

Elderly have physiological changes following their age and many of them are manifesting in the oral cavity and surrounding tissues. Clinically, the mucosa of the oral cavity becomes thinner, smoother and dry. Histological changes are followed by dry mouth. The 
lack of saliva is generate due to the weak function of the saliva gland. Dry mucosa becomes susceptible to injury or infection, especially in the prosthetic patients, wearers of removable dentures (3).

In patients with impaired renal function, $90 \%$ of patients have symptoms of uremia in the mouth. Symptoms in the oral cavity are part of the systemic illness and should be observed, not separately from the underlying disease. Most striking signs are ammonia, inflammatory changes in mucosa of the oral cavity (uremic stomatitis, gingivitis) and dry mouth. Health of the oral cavity in many older chronic kidney patients is bad. Due to uremia and kidney failure, the tendency to bleeding and anemia is increase. This is the main reason why are these patients prone to bleeding from the gingiva, ulceration and purpura, or petechial lesions throughout the mucosa of the oral cavity. The usual occurrence in their mouth is hematoma after surgery. In dialysed patients, dental procedures and surgical interventions should be taken several hours after dialysis, possibly the second day in the morning when there are no uremic toxins in the blood. Platelets and complete bloodline tests provide the dentist important guidelines for bleeding and anemia control. The patient should not be shrivel on the dental chair too long in the sitting position and should be allow leaving the chair during long-lasting dental procedures, every hour, and walk through the waiting room (4-6).

\section{Renal Diseases Influences on Dental Therapy}

An integral part of the kidney transplantation preoperative procedure is the exclusion of the foci in the oral cavity. Patients should refer with orthopantomogram to the dentist's for examination. The dentist should detect and treat potential infections before kidney operation. If treatment does not lead to complete healing, it is better to remove the tooth than to risk the infection after transplantation and inclusion of the immunosuppressive therapy (7).

Because of the nature of the disease and the involvement of the kidney function, these patients often do not consider that the oral cavity health is of high priority. Ninety percent of patients with chronic renal disease have changes in the oral cavity. Changes affect the soft tissue of the oral cavity and bone (8).

The urethral bad breath from the oral cavity is induce by ammonia and is more pronounce if adequate oral hygiene is not perform. High concentrations of urea in the blood lead to high concentrations of urea in the saliva releasing ammonia. Due to the chronic nature of the illness and the large involvement of patients about their illness, they often ignore oral hygiene.

At the patients on hemodialysis, the use of anticoagulants during dialysis may increase the tendency to bleed after dialysis. It is therefore recommend performing dental procedures in the days between dialysis. It would be advisable before the procedure to do a blood test and a small coagulogram, and ensure good local hemostasis-compression and suture, if needed, after oral surgery and tooth extraction $(9,10)$.

Breathing on the mouth due to acidosis or accumulation of fluid in the lungs can also cause symptoms of dry mouth. Patients in the terminal stage of renal disease produce less saliva with and without stimulation. Due to all of the above, it is necessary to take a detailed history to detect the cause of dryness in the mouth (11).

These patients should try to replace certain drugs that cause dryness to others whenever possible. Acidosis and cardiac decompensation should be treat. Adequate oral hygiene is important, at least after each meal and before bedtime. It is not recommend to use a flask of dental paste, since if resorb, it can negatively effect on renal osteodystrophy. Food and drink rich in salt and sugar should be reduce. Dialyzed patients who have significantly reduced diuresis are limited in fluid intake accompanied by dry mouth. To decrease dryness it is very helpful the application of substances that increase salivation (candies, chewing gum, artificial saliva).

Patients in the terminal phase of kidney failure often have a changed sense of taste, and some of the patients complain about the presence of strange metal taste in the mouth. High levels of urea, dimethylamine and trimethylamine, as well as low levels of zinc, can modify the taste of these patients. The prevalence of caries is lower in patients in the terminal phase of renal failure than in the general population. This effect attributes the effect of urea and its metabolites in saliva that inhibit bacterial growth and neutralize bacterial acids in the elderly.

Gingival hyperplasia as a side effect of drug administration is one of the most commonly described 
oral manifestations in patients with kidney failure. This may be due to the use of cyclosporine; frequently used immune suppressants in transplanted patients and / or calcium channel blockers (nifedipine, amlodipine, diltiazem, verapamil) used in pre dialysis patients or dialysis patients for the treatment of hypertension. Poor oral hygiene and simultaneous administration of two or more drugs that may exert hyperplasia may exacerbate the condition of hyperplasia. Hyperplasia is reversible, by reducing or by omitting the medications dose that cause this effect. (12).

Because of the immune compromised condition due to uremia, the use of immunosuppressive drugs, also the reduced secretion of saliva and dryness, patients are more likely to have oral cavity infections. There is a change in the microflora of the oral cavity to virulent Gram-negative microorganisms, fungal infections (candidiasis) and viral infections. In patients in the terminal phase of renal insufficiency and transplantation, each odontogenic infections should be aggressively treat.

Patients treated with long-term immunosuppression have an increased tendency to develop tumors in the oral cavity, Kaposi's sarcoma and non-Hodkin's lymphoma.

As a part of renal osteodystrophy, demineralization, trabecularity and loss of the maxillary and mandibular cortical bone, bone damage (bone fractures) during dental surgery (tooth extraction) may occurs. Patients also have greater tooth mobility. because of the immune compromised condition due to uremia and use of immunosuppressive drugs, but also the reduced secretion of saliva and dryness. Therefore, these patients are more likely to have oral cavity infections.

\section{ConCLUSIONS}

Elderly are affect usually by one or few chronic diseases and have physiological changes following their age. Their health problems affects the care of mouth and teeth. Medications that they take may interact with medication and the procedures used in general dental practice. Changes in the oral cavity have $90 \%$ of patients with chronic renal disease. Gingival hyperplasia as one of the side effects of drug administration is one of the most commonly described oral manifestations in patients with kidney failure. It would be advisable before surgical procedures to do a blood test and a small coagulogram. After oral surgery and tooth extraction of the patients in the final phase of kidney failure it is very important to ensure good local hemostasis-compression and seizures, if needed, because of their tendency to have postoperative bleeding. As a part of renal osteodystrophy, demineralization, trabecularity and loss of the maxillary and mandibular cortical bone, results in bone damage (bone fractures) during dental surgery (tooth extraction) may occurs. The renal diseases that affects the mouth conditions are in need to threat parallel with oral diseases and symptoms they provide in the mouth of elderly patients. The proper maintaining of oral hygiene in elderly is of exceptional importance to avoid general health and renal disease complications.

\section{REFERENCES}

[1] Ćatović A at al.. Gerontostomatologija, Zagreb, Medicinska naklada, 2010.

[2] Baumgartner W,Schimmel M,Frauke Müller. Oral health and dental care of elderly adults dependent on care. Swiss Dental J 2015; 125: 417-426.

[3] Bots-Vantspijker P, Vanobbergen J, Schols J i sur. Barriers of delivering oral health care to older people experienced by dentists: a systematic literature review. Community Dent. Oral Epidemiol. 2014; 42: 113 - 121.

[4] Ćatović A. et al. Dentalna medicina starije dobi u praksi, Zagreb, Medicinska naklada, 2018.

[5] Ruokonen H., Nylund K., Furuholm J. at al. Oral Health and Mortality in Patients With Chronic Kidney Disease J Periodontol. 2017; 88(1): 26-33.

[6] Tiwari V, Saxena V, Bhambhal A, at al. The oral health status of patients with renal disease in central India: a preliminary study. J Ren Care. 2013; 39(4): 208-13.

[7] Meier-Kriesche HU, Ojo AO, Hanson JA, Kaplan B. Exponentially increased risk of infectious death in older renal transplant recipients. Kidney Int. 2001; 59: 1539-43.

[8] Klassen JT, Krasko BM. The dental health status of dialysis patients. J Can Dent Assoc. 2002;6 8: 34-8.

[9] Titilope A Adeyemo, Wasiu L Adeyemo, Adewumi 
Elderly Dental Patients with Renal Diseases

Adediran, Abd Jaleel A Akinbami, Alani S Akanmu; Orofacial manifestations of hematological disorders: Anemia and hemostatic disorders; Indian Journal of Dental Research; 2011; 22: 454-461.

[10] Bhandal S, Pattinson J. How to support patients taking new oral anticoagulant medicines. Clinical Pharmacist. 2013; 5: 268.
[11] Kshirsagar AV, et al. Periodontal disease adversely affects the survival of patients with end-stage renal disease. Kidney Int. 2009; 75: 746-751.

[12] Ciavarella D, Guiglia R, Campisi G, Di Cosola M, Di Liberto C, Sabatucci A, et al. Update on gingival overgrowth by cyclosporine $\mathrm{A}$ in renal transplants. Med Oral Patol Oral Cir Bucal. 2007; 12: E19-25

Citation: Ćatović Adnan, Ćatović Džana, Ćatović Dina. Elderly Dental Patients with Renal Diseases. Open Journal of Geriatrics. 2019; 2(1): 14-17.

Copyright: (C) 2019 Ćatović Adnan, Ćatović Džana, Ćatović Dina. This is an open access article distributed under the Creative Commons Attribution License, which permits unrestricted use, distribution, and reproduction in any medium, provided the original work is properly cited. 